\title{
Can synoptic patterns influence the track and formation of tropical cyclones in the Mozambique Channel?
}

Chibuike Chiedozie Ibebuchi ( $\sim$ chibuike.ibebuchi@uni-wuerzburg.de )

University of Würzburg

\section{Research Article}

Keywords: Circulation type, Tropical cyclones, Hourly classification, Mozambique Channel, Africa south of the equator

Posted Date: February 8th, 2021

DOI: https://doi.org/10.21203/rs.3.rs-200536/v1

License: (c) (i) This work is licensed under a Creative Commons Attribution 4.0 International License. Read Full License

Version of Record: A version of this preprint was published at AIMS Geosciences on January 1st, 2022. See the published version at https://doi.org/10.3934/geosci.2022003. 


\section{Abstract}

The influence of large-scale circulation patterns on the track and formation of tropical cyclones (TCs) in the Mozambique Channel is investigated in this paper. The output of the hourly classification of circulation types (CTs), in Africa, south of the equator, using rotated principal component analysis on the T-mode matrix (variable is time series and observation is grid points) of sea level pressure (SLP) from ERA5 reanalysis from 2010 to 2019 was used to investigate the time development of the CTs at a sub-daily scale. The result showed that at specific seasons, certain CTs can persist for a longer time so that their features overlap with other CTs. CTs with synoptic features favorable for the development of TC in the Mozambique Channel were noted. The 2019 TC season in the Mozambique Channel characterized by TC Idai in March and TC Kenneth afterward in April was used in evaluating how the CTs designated to have TC characteristics played role in the formation and track of the TCs towards their maximum intensity. The results were discussed and it generally showed that large-scale circulation patterns might influence the formation and track of the TCs in the Mozambique Channel especially through the different modes of variability associated with the western branch of the Mascarene high.

\section{Introduction}

Harr and Elsberry (1995) suggested that the modes of variability in a large-scale circulation can be represented by individual circulation types (CTs), and these modes can influence the formation and track of tropical cyclones (TCs) over the tropical western North Pacific. Thus it is worthwhile to investigate how physically meaningful synoptic patterns in Africa, south of the equator, might influence TC activity in the Mozambique Channel, which experiences intense TC seasons endangering lives and properties especially in Madagascar (Jury et al. 1993).

The most application of circulation typing has been focused on its usage to explain the variability of surface variables. Vicente-serrano and LópezMoreno (2006) noted that linking circulation patterns to a surface variable can explain the intensity and spatial variation of the variable. However, it should be equally considered that the large-scale variability associated with cyclonic and anti-cyclonic systems, which the circulation typing tends to characterize in terms of recurrent patterns, form the basic dynamics through which the large-scale circulations influence surface variables.

Tropical cyclones (TC) are low-pressure systems intensely rotating cyclonically that form over the tropical oceans (Smith 2006). They are recurring phenomena in the southwestern Indian Ocean (Ash and Matyas 2012). Based on the maximum wind speed sustained, in the southern hemisphere, they can be characterized as tropical storms, depressions, or cyclones. However, for simplicity, tropical cyclones will be used in this work to cover intense cyclonic systems in the Mozambique Channel. The usual periods for the occurrence of TC, in the southern hemisphere, are during peak austral summer and austral autumn (December - March). This is because these periods are usually characterized by higher sea surface temperature (SST), unstable atmosphere necessary for moist convection, and lower tropospheric vertical shear. The lag, at which TC occurs, amidst the period of maximum insolation, is due to the high heat capacity of ocean waters, which causes them to take several weeks to reach high temperatures. SST is significantly related to the storm intensity (Pillay and Fitchett 2019). Oguejiofor and Abiodun (2019) noted that an increase in SST by $2^{\circ} \mathrm{C}$ generally increases the intensity of TCs. Gray (1968) explained that the inter-tropical convergence zone (ITCZ), which moves southward in austral summer, brings about the necessary convergence and vorticity for the formation of TC. He noted that in addition to lower SST, strong vertical wind shear and lack of typical ITCZ over the South Atlantic Ocean are reasons why TC is rare at this basin. In the south Indian Ocean, Fitchett (2018) reported that the frequency of TCs that reached a category five (i.e. the strongest category of storms) have increased since 1989. Under global warming, at a critical threshold of $2^{\circ} \mathrm{C}$, the number of TCs making landfall over southern African is projected to decrease (Muthige et al. 2018). Also, Malherbe et al (2013) added that under global warming, for the latter part of the 21st century, due to changes in large-scale atmospheric temperature, pressure, and wind profiles of the southern African regions and the adjacent oceans, the preferred landfall position of the TC systems is projected to shift northward over the southern Africa sub-continent.

In the Mozambique Channel, atmospheric conditions are favorable for the development of TCs due to high SST of about $26^{\circ} \mathrm{C}-28^{\circ} \mathrm{C}$ in austral summer (Pillay and Fitchett 2020) and weak vertical wind shear (Jury and Pathack 1991). According to Malan et al. (2013), values of TC heat potential (i.e. above 40) needed for TC intensification might still be present in the Mozambique Channel up to May. TC within the southwest Indian Ocean occurs on average about three times a year over Madagascar and Mozambique (Malherbe et al. 2011). Most TCs in the Mozambique Channel tracks southeastwards, after approaching Madagascar it recurves into the south Indian Ocean (Kliman and Reason 2008). Also variability in the strength and position of the Mascarene high influences both the formation and track of TC in the Mozambique Channel (Xulu et al. 2020), especially through the direct influence it has on teleconnections such as the subtropical Indian Ocean dipole (Reason 2002) and southeast wind anomalies that penetrate the Channel. Repeated tropical cyclogenesis in the Mozambique Channel according to Chikoore et al. (2012) can be attributed to warm SST in the southwest Indian Ocean and anomalous easterly circulations. Reason and Keibel (2004) explained that even though it is less likely that landfall associated with TC will penetrate the interior southern African mainland and the east coast of southern Africa due to the relatively dry interior plateau that covers most of the regions, synoptic conditions coupled with SST anomalies and atmospheric circulations over the Indian Ocean might favour an unusual penetration of TC in the aforementioned regions. A study by Malherbe et al. (2011) suggested that the strengthening of the semipermanent high-pressure systems over the eastern parts of southern Africa might influence the track characteristics of TCs, resulting in the lowpressure system tracking into southern Africa. 
Large scale low-frequency modes of variability at the south Indian Ocean such as the Madden-Julian Oscillation, El Niño Southern Oscillation (ENSO), the subtropical Indian Ocean dipole (SIOD), the Southern Annular Mode (SAM), and the Indian Ocean Dipole (IOD), have been noted to influence the frequency of TC occurrence and the spatial pattern of TC in the south Indian Ocean (e.g. Gray and Sheaffer 1991). Matyas (2015) noted that when the SIOD and the SAM are negative, the formation of TC tends to occur north of the Mozambique Channel and vice versa. Also, he noted that the teleconnections especially the SAM and the Madden Julian Oscillation influence perceptible water values. According to Pillay and Fitchett (2019), the Dipole Mean Index and the SAM coincide with the highest landfall years and also influence the latitudinal and longitudinal track trajectories of TC in the southwest Indian Ocean. Here the focus is on investigating how the recurrent synoptic situations characterized by large-scale variability in cyclonic and anti-cyclonic circulations in Africa, south of the equator, influence the track and formation of TCs in the Mozambique Channel.

Mofor and Lu (2009) explained TCs as a little rotating earth on which a complete set of eigenmodes of a dynamic system exist. Applying vector empirical orthogonal function analysis and fuzzy algorithm to obtain recurrent patterns over the tropical western North Pacific, Harr and Elsberry (1995) concluded that CTs over the basin are related to TC characteristics, revealing their formation and track types. A challenge in classifying circulation patterns is that the recurrent patterns characterized by the SLP or any other geophysical parameter that explains atmospheric circulation are continuum - the classified data is continuous. In the actual sense, atmospheric processes are fuzzy (i.e. inherently imprecise) thus that they cannot be accurately described by a classification scheme based on (binary) classical logic which results in precise classifications. Fuzzy logic is the best way to describe the atmospheric phenomena to reach a physically meaningful insight (Gong and Richman 1995). In as much as the purpose of modeling is to simplify reality and eliminate overlapping, such simplifications that use deep learning algorithms often reach precise decisions, but providing no physical justification for it, so that in the context of circulation typing, CTs are commonly used as a black box rather than actual synoptic situations which are fuzzy and overlap. According to Gong and Richman (1995), obliquely rotated principal component analysis when used as a classification tool is inherently fuzzy and allows the overlapping of the classified geophysical parameter; hence it is used as the classification approach in this paper. Besides, when applied to a field that explains atmospheric circulation and represented in the T-mode structure, it can satisfactorily reproduce predefined flow patterns in a given region so that the probability of specific weather events associated with a given flow pattern is revealed (Richman 1981; Compagnucci and Ruiz 1992; Compagnucci and Richman 2008).

The continuum nature of atmospheric circulation implies equally that to understand atmospheric circulation at a given time instant, one needs a clear picture of the previous history of the patterns that occurred. Generally, the transition from one CT to the other is not likely to be spontaneous but might occur at a sub-daily scale since surface pressure can vary at an hourly scale. Thus to get the best insight on this issue, using ERA5 reanalysis data set (Hersbach et al. 2020) which has SLP, spatially and temporally homogeneous with other fields at an hourly resolution, and using Africa, south of the equator, as the study region, this study investigates the hourly time development of the CTs and the ability of the CTs examined at a subdaily scale to explain the track and formation of TCs in the Mozambique Channel using the 2019 TC events of TC Idai and TC Kenneth as reference.

\section{Data And Methods}

Hourly SLP data set from 2010-2019 and daily SLP data set from 1979-2019 were obtained from ERA5 reanalysis (Hersbach et al. 2020 ) and NCEPNCAR reanalysis (Kalnay et al. 1996) respectively. Both reanalyses data sets were interpolated to a common longitude and latitude using bilinear interpolation. Maoyi et al. (2018) reported that the reanalysis data sets (ERA-Interim in particular) perform low in producing TCs with a deep pressure center as low as the observed; thus it is acknowledged that the reanalysis data sets might have limitations when used to study TC.

Fig. 1 shows the study region for the CT classification $\left(0-50.25^{\circ} \mathrm{S} ; 5.75-55.25^{\circ} \mathrm{E}\right)$. It was chosen to capture the Mozambique Channel, adjacent ocean to the east coast of Madagascar, the west to east movement of the subtropical high-pressure system, and the polar fronts - during its northward track. The classification of the CTs is completely eigenvector based. It involved the application of obliquely rotated PCA on the T-mode correlation matrix of the SLP field (Richman 1986). Singular value decomposition was used to obtain the PC scores and the eigenvectors. The PC scores capture the input patterns and the eigenvectors localize the input patterns in time (Compagnucci and Richman 2008). The number of the retained component was based on the separation of the eigenvalues as recommended by North et al. (1982) and by ensuring that each added component uncovers a unique pattern. To make the eigenvectors responsive to rotation they were weighted with the square root of their corresponding eigenvalues so that they become loadings longer than a unit length. The oblique rotation that was made at a power of 2 makes the patterns to be physically interpretable by eliminating the orthogonality constraint and maximizing the number of near-zero loadings so that each retained component clusters unique days with similar spatial pattern (Richman 1981, 1986). The absolute value of the loadings reflects an important signal and only high loadings contribute to the PC scores (Compagnucci and Richman 2008). Hence even though the classified patterns are inherently fuzzy, they were hardened using a subjective threshold of (Richman and Gong 1999) so that each component yields clusters of negative and positive loadings above the threshold. The reason for this is to improve the internal cohesion and external isolation of the classes. Increasing the threshold will reduce the overlapping of the classified days and will result in a more simplified classification; however, it will further eliminate useful information on group membership (Gong and Richman 1995). Despite the hardening, a day can still have its loading greater than the threshold under more than one retained component, so that overlapping of the classified variables is possible, making the classification physically meaningful. Also to ensure that the patterns are not artifacts of the selected reanalysis data set, choice of the analysis period and temporal resolution, the daily classification from NCEP was used to validate the sub-daily classification from ERA5 based on the reproduction of the input patterns (PC scores), their eigenvalues and the CTs with their occurrence frequencies. Furthermore, the classification has not been limited only to the TC season since there are no clear boundaries in the

Page $3 / 16$ 
seasonality of CTs so that it will not be accurate to claim that there are summer or winter CTs in the absolute sense, even though a CT might have a high tendency to dominate in a given season. In reality, a CT dominant in summer might still (in rare conditions) occur in winter and vice versa; the idea of seasons is equally fuzzy. Thus it might be an advantage to use the complete data set in the circulation typing, and then further analyze the annual cycle of the CTs to isolate the CTs that tend to be dominant at a given season, by so doing the probability of a CT occurring in a season when it is likely to occur will be retained.

The Mozambique Channel is among the basins where TC can develop. A study by Matyas (2015) analyzed the atmospheric conditions during TC events in the Mozambique Channel using, SST, precipitable water, and vertical wind shear. Here variations in the position/structure and amplitude of SLP in the Channel as presented by the classified CTs, together with the composites of precipitable water, wind vector at $850 \mathrm{hPa}$, and relative vorticity at $850 \mathrm{hPa}$ were used in isolating major CTs with TC characteristics in the basin. The 2019 TC season in the southwest Indian Ocean characterized by two significant cyclonic events in the Mozambique Channel (i.e. the TC Idai and TC Kenneth) were used as reference periods in examining if the CTs designated to characterize conditions under which a TC might develop in the Channel, played some role during the TC events. In each case, hourly variations in SLP in 4 days were examined based on investigating the CTs assigned to the hours of these days by the classification scheme. The 4 days is a lag of two days before the TC reached its first maximum intensity, the day the TC reached its first maximum intensity, and the following day. After the occurrence/persistence of the CTs with TC characteristics was checked for the 24 hours in each day, the mean of SLP and wind vector at $850 \mathrm{hPa}$ in each of the days was computed, and field correlation was done between the mean SLP of the day and the mean SLP field representing the CT with TC characteristics; higher correlation suggests that the signal of the CT was significant on that day, irrespective of the continuum nature of the CTs. The overreaching goal of the analysis is to check if the time development presented by the hourly occurrence of the CTs validates that the types designated to possess TC characteristics in the basin, occurred/persisted and have contributed to the formation and track of the TC system.

\section{Results}

\subsection{Validation of the hourly_CTs from ERA5}

Fig. 1 shows the input patterns from the 9 retained components as classified from ERA5. The congruence coefficients from Table 1 between the patterns from ERA5 and NCEP-NCAR shows a one to one correspondence and were generally greater than 0.95 , indicating that the input patterns presented by the scores, were well reproduced in each case. The CTs are designated by the mean SLP map in Fig. 2 . Classification of the CTs in the study region at higher horizontal resolutions and with other reanalysis products and climate models resulted in input patterns with the same ordering as in Fig. 1 (not shown) except that type 7 preceded type 6 in some cases, and also the spatial structure of 8+ shows less stability, otherwise the CTs are stable in all cases even with a one to one correspondence suggesting that they are actual synoptic situations in the study region.

Table 1: Congruence coefficients between scores from ERA5 and corresponding scores from NCEP-NCAR

\begin{tabular}{|ll|}
\hline Component & Congruence coefficient \\
\hline 1 & 0.99 \\
\hline 2 & 0.99 \\
\hline 3 & 0.99 \\
\hline 5 & 0.99 \\
\hline 6 & 0.96 \\
\hline 7 & 0.95 \\
\hline 8 & 0.98 \\
\hline 9 & 0.93 \\
\hline
\end{tabular}

Fig. 3 shows the relative frequency of occurrence of the CTs from the hourly ERA5 classification and the daily classification from NCEP-NCAR. It can be seen that regardless of the choice of the reanalysis product, temporal resolution, and classification period, the relative frequency of occurrence of the CTs shows satisfactory stability. 1+, 2+, 3+, and 4+ have a relatively higher probability to occur. They can be understood as mean patterns based on their persistence for a longer time. $1+$ is the most frequent and the climatology of atmospheric circulation in the region. The annual occurrence of the CTs (not shown) indicated that $1+$ is dominant in austral winter, whereas $3+$ is specifically the austral summer climatology since it is the most frequent austral summer pattern. 2+ dominates almost in all seasons and 4+ also is dominant in austral summer. The input patterns of type 3 and type 4 (Fig. 1) indicate two major scenarios of variability in the semi-permanent high-pressure systems during austral summer. Type 3 (i.e. $3+$ in this case) shows the west to east movement of the semi-permanent high, which ridges through the Agulhas current towards eastern South Africa. Type 4

Page $4 / 16$ 
(i.e. 4+ in this case) shows a scenario where the western portion of the Mascarene high weakens and the mid-latitude disturbances track further north, allowing the cyclonic system from the Mozambique Channel to move further southwest since atmospheric blocking by the western branch of the Mascarene high is diminished.

\section{$\underline{3.2 \text { Selections of CTs with tropical cyclone characteristics }}$}

TC in the southern hemisphere is usual in austral summer and early austral autumn. Considering the high heat capacity of ocean water, the SST threshold (about $26^{\circ} \mathrm{C}-28^{\circ} \mathrm{C}$ ) necessary for the development of TC can be slowly attained, resulting in why early austral autumn might be the period favorable for TC development in the Mozambique Channel. From the input patterns in Fig. 1, type 9 clearly shows a strong negative anomaly in the Mozambique Channel, apparently blocked by a positive anomaly positioning at the western branch of the Mascarene high. From Fig. 2 , $9+$, a strong cyclonic anomaly subjected to atmospheric blocking by the Mascarene high is evident. Based on the composites from precipitable water (PW), wind vector at $850 \mathrm{hPa}$ (Fig. 4), and relative vorticity (not shown), 9+ is the major CT that presents a synoptic state favorable for TC in the Mozambique Channel. According to Jury and Pathack (1991) during TC season in the Mozambique Channel, lower level winds are westerly at about $15^{\circ} \mathrm{S}$ northward. This is evident in 9+ from Fig. 4; since the strong cyclonic anomaly adjusts the cross-equatorial easterly winds to become predominantly westerly towards the northern part of the Channel. Concerning the strong correlation between SST, SLP, and PW and also that the transfer of energy that strengthens the radial circulation within a TC mainly comes through the evaporation of water into the atmosphere, PW is an important field in the monitoring and prediction of the intensity and track of TC. Fig. 4 shows that for 9+ PW is relatively enhanced in the Channel and at the east coast of Madagascar. An enhancement of PW implies a drop in SLP and an increase in SST. At the upper levels, PW is equally related to the mass of clouds, thus even though this analysis has not explicitly incorporated more upper-level variables in the selection of CTs with TC characteristics, PW might still be sufficient to approximate an atmospheric condition under which TC might develop. From Fig. 5, the annual occurrence of 9+ dominates from February to April, which corresponds to the TC season in the southern hemisphere.

$6+$ is another CT selected to have TC characteristics though with a lesser intensity of the low-pressure system in the Mozambique Channel compared to $9+$, and also with a different track altogether. Its input pattern from Fig. 1 shows a strong anomaly at the southern landmasses, extending eastward into the southwest Indian Ocean. Unlike in 9+, the western branch of the Mascarene high is weakened allowing the cyclonic system to progress further southwest towards the Agulhas current. Its dominating period from Fig. 5 is in the peak of austral summer when continental heating is highest; suggesting that diabatic heating might play a role in generating the positive SST anomalies in the southwest Indian Ocean. It is equally evident that under $6+$ cross-equatorial easterly winds are well expressed, transporting moisture from the tropical Indian Ocean into the Channel. PW under $6+$ extends also southwest, following the weakening of the western branch of the Mascarene high.

$3+$ and 4+ though not explicitly selected as TC types should be noted. Since they are austral summer mean patterns, their persistence for a longer time, relative to the winter dominant CTs is crucial in creating the long-term atmospheric condition under which TC might develop in the Channel. Moreover, the persistence of their signal will aid in enhancing the TC characteristics of the CTs designated to have TC features, whereas the occurrence of winter dominant CTs such as 4- and 6-, associated with the dominance of high-pressure system over the southwest Indian Ocean might have a buffering effect on the tropical cyclonic characteristics of the TC types - related to drier air which can inhibit moist convection. 5- presents a synoptic state similar to $6+$, concerning a weak state of the western branch of the Mascarene high, thus allowing warm SST in the southwest Indian Ocean. However, Fig. 4 shows that PW is higher north of Madagascar suggesting that TC might develop mainly towards the north of the Mozambique Channel under this synoptic state. 7- is also similar to 9+ in terms of the strength of the circulation in the south Indian Ocean high pressure, though the circulation appears relatively stronger under this synoptic state, with the cyclonic system in the Mozambique Channel being weaker. The strong easterly wind associated with a stronger south Indian Ocean high-pressure might aid in steering TCs westward towards southern Africa. However, as shown in the case of 9+ (Fig. 4) should the intensity of the cyclone in the Mozambique Channel be high, easterly trade winds might be adjusted to westerly rather than steering the cyclonic system to move westward. Hence the mean wind in the Channel will decide if the TC can be steered by either the southeast or northeast trade winds. Moreover, the convergence of the easterly winds in the Channel can influence the storm development through the vorticity it induces. To this end, 9+ and 6+ are the major CTs with synoptic states favorable for the development of TC in the Mozambique Channel, whereas 3+ and 4+ are vital for creating the long-term atmospheric conditions for both the development of the TC and the occurrence of the TC types, whereas 5- and 7- might play vital roles in the development of TC north of the Channel and in its track. Generally, $9+$, 7- and 3+ commonly enhance blocking of the cyclone from moving further south; on the other hand, $6+$, 5- and 4+ commonly feature the weakening of atmospheric blocking by the Mascarene high, allowing the TC to move further south.

Correlation analysis between the time series of the patterns and teleconnection indices such as the Nino3.4 index, SAM index, IOD index, and the SIOD index revealed that 5 - and $6+$ are related to ENSO $(R=0.48$ and $R=0.31$ respectively); $9+$ is related to the IOD ( $R=0.42) ; 7$ - is related to $S A M$ $(R=0.25)$ and $6+$ is related to the SIOD $(R=0.33)$. This shows that the CTs might as well be constrained by other low-frequency modes of variability. Specifically, the strong relationship between ENSO and type 5 (i.e. 5- and 5+) reveals that during the different phases of ENSO the western branch of the Mascarene high can be weakened (as in 5-) or strengthened (as in 5+). The different phases of the IOD can be related to type 9 through SST anomalies in the Mozambique Channel. The positive and negative phases of the SAM can be related to type 7 through suppression of the easterly 
circulation of the Masacerene high when the polar fronts track northward (as in 7+) and enhancement of the circulation at the Mascarene high when the polar fronts track poleward (as in 7-). Finally, the SIOD is related to type 6 since in its positive phase the southwest Indian Ocean is anomalously warm, enhancing cyclonic activity over there as in $6+$, while in its negative phase the reverse can be inferred as in $6-$. Thus the CTs are related to these teleconnections directly through the enhancement and weakening of the easterly anomalies at the Mascarene high and SST anomalies at the southwest Indian Ocean.

\subsection{TC season in the Mozambique Channel and influence of the selected TC circulation types}

In this section, it will be investigated if the hourly occurrence of CTs, according to the classification output, influences the time development and track of TCs in the Mozambique Channel. For this purpose, the 2019 TC events of TC Idai and TC Kenneth were analyzed. In each case, the hourly occurrence of the CTs for two days before the TC reached its first maximum intensity, the day the TC reached its first maximum intensity, and a day after the TC reached its first maximum intensity were investigated. Table 2 shows the hourly occurrence of CTs, according to the classification output and for the aforementioned days. It can be seen that the CTs designated as mean patterns persist for a longer period and overlap with other CTs, and also generally, the hourly occurrence of the CTs reveal that the CTs do not readily change at an hourly scale, thus a 3 or 6 hourly classification can still be optimal while equally reducing computation time. It should be noted that a change in pressure pattern (and wind pattern) at a 3 hourly scale is realistic and might be of predictive skill in the direction TC systems will likely travel - TCs will likely move to regions where the pressure drops rapidly. Also, a large drop in pressure ahead of a cyclone might imply that the cyclone is deepening. This is the advantage that analyzing a sub-daily occurrence of the CTs can present.

Table 2: Hourly occurrence of the CTs from the ERA5 classification output for the selected days of the 2019 TC season of TC Idai and TC Kenneth

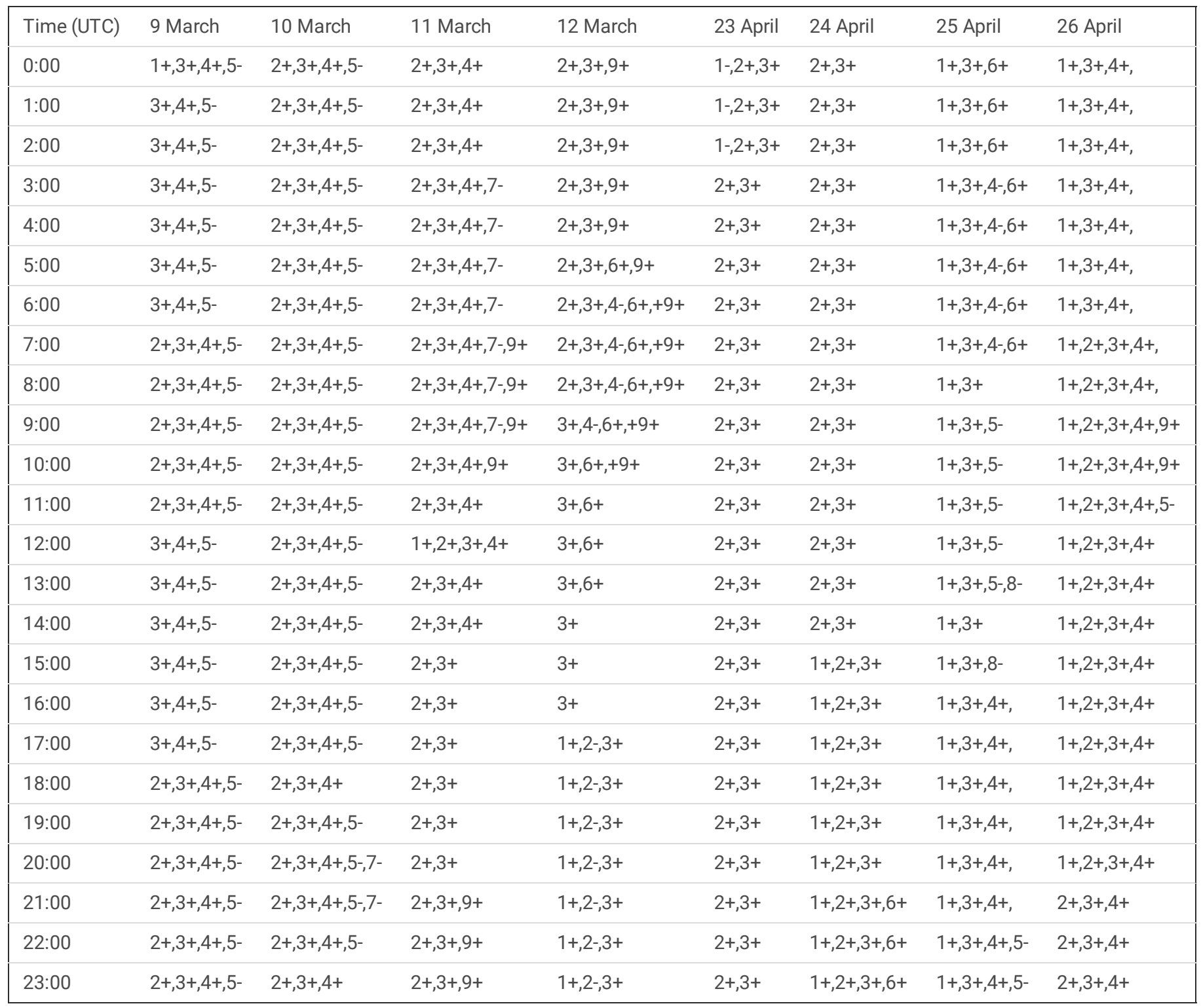


Fig. 6 shows the mean SLP and vector wind field at $850 \mathrm{hPa}$ for the selected days and Table 3 presents the field correlation between the mean SLP patterns for each day and the mean SLP pattern for the selected CTs with TC characteristics. The analyzed days for TC Idai are from 9 March to 12 March. From 9 March to 10 March 19:00 UTC, long persistence of 2+, 3+, 4+, and 5- can be seen (Table 2). Recall that 3+ and 4+ are austral summer mean patterns, and 4+, similar to 5-, presents a weaker state of the western branch of the Mascarene high. Hence the persistence of the combination of 4+ and 5-might suggest a synoptic state associated with a weaker circulation at the western branch of the Mascarene high. This was evident from Fig. 6 on 9 March - the semi-permanent high-pressure system appears weakened over the southwest Indian Ocean and relatively more southward, similar to the mean pattern of 5- in Fig. 2. A TC can be seen also towards the east coast of northern Mozambique. Recall that 5- favors the development of TC north of the Channel. On 10 March between 20:00 UTC and 21:00 UTC, 7- associated with stronger circulation at the south Indian Ocean high-pressure occurred and this might have contributed to why the Mascarene high moved a bit northward and strengthened; following a possible strengthening of convergence by the ITCZ as a result of stronger southeast trade winds penetrating the Mozambique Channel, the TC appears to develop further. Table 3 shows that on 9 March and 10 March, the SLP signal of 5- tends to be relatively dominant. On 11 March $9+$ persisted from 7:00 UTC to 9:00 UTC; Table 3 shows that its signal dominated the others on this day. The SLP and wind vector pattern of 11 March shows equally a strengthening of the south Indian Ocean high-pressure and convergence of easterly winds (adjusted to westerly) in the Channel. The meteorological history of TC Idai notes that it reached its first peak intensity by 12:00 UTC on 11 March (Meteo France La Reunion 2019). Also between 21:00 UTC of 11 March and 10:00 UTC, of 12 March, 9+ persisted again so that from Table 3 its SLP signal dominates again on 12 March. Furthermore, the mean SLP and wind vector pattern on 12 March shows that the south India Ocean high-pressure strengthened more, further blocking the TC from progressing southward. On the same day (i.e. 12 March) between 5:00 UTC and 10:00 UTC, 6+ occurred together with 9+, but from Table 3 , the signal of 9+ tends to persist relatively. It is also remarkable that 4- occurred from 6:00 UTC to 9:00 UTC. 4- is a winter dominant pattern and Fig. 2 suggests that through the subsiding motion (enhanced anticyclone) it brings in the southwest Indian Ocean, it might inhibit deep convection in the basin. Its occurrence implies that the TC might further weaken, and from the meteorological history of TC Idai (Meteo France La Reunion 2019), it was reported that relative to its strength on 11 March, Idai weakened on the 12 March at the same time (6:00 UTC) the classification output noted that 4- started to occur. According to Oguejiofor and Abiodun (2019), an increase in surface pressure over a TC basin can be related to a decrease in SST, maximum precipitation rate, and wind speed. In a scenario that the classification is solely focused on the TC season, the occurrence of a winter type will not be captured, and this might be a further example of the pitfalls following the oversimplification of synoptic classifications.

Table 3: A measure of the signal of the CTs with TC characteristics during the selected days of the 2019 TC season of TC Idai and TC Kenneth

\begin{tabular}{|lllllllll|}
\hline CT & 9 March & 10 March & 11 March & 12 March & 23 April & 24 April & 25 April & 26 April \\
\hline $5-$ & 0.68 & 0.74 & 0.54 & 0.47 & 0.55 & 0.63 & 0.81 & 0.80 \\
$6+$ & 0.44 & 0.58 & 0.59 & 0.56 & 0.55 & 0.73 & 0.78 & 0.75 \\
\hline $7-$ & 0.46 & 0.66 & 0.66 & 0.46 & 0.57 & 0.67 & 0.67 & 0.76 \\
$9+$ & 0.61 & 0.74 & 0.73 & 0.69 & 0.72 & 0.78 & 0.75 & 0.74 \\
\hline
\end{tabular}

Coming to TC Kenneth, on 23 April and 24 April the SLP and wind vector field from Fig. 6 shows that the TC was situated north of Madagascar with the Mascarene high northward and strengthened. The classification output showed that 2+ and 3+ which are both associated with the west to east movement of the semi-permanent high-pressure system, ridging through the Agulhas region to eastern South Africa, exceptionally persisted from the onset of 23 April till 21:00 UTC on 24 April when 6+ co-occurred with them. $6+$ persisted for the rest of day till 7:00 UTC of 25 April. Recall that 6+ implies a weakening of the western branch of the Mascarene high, enabling the TC to progress further southwest. Also, 5- with a similar feature as $6+$ persisted for 5 hours on the same day between 9:00 UTC and 13:00 UTC. 8-, from Fig. 2, equally supports weakening of semi-permanent highpressure system; from Table 2 it can be seen to have occurred at some points on 25 April. Also between 22.00 UTC and 23:00 UTC 5- occurred again. The implication of the persistence of the CTs that favors the weakening of the western branch of the Mascarene high is reflected in the mean map for 25 April (Fig. 6). Cross equatorial easterly winds are stronger, penetrating further southwest and steering the TC towards the east coast of northern Mozambique. Southeast winds are weakened with the Mascarene high situated further southeast and cyclonic circulation tends to enhance southwest towards the Agulhas region. The meteorological history of TC Kenneth reported that it reached its first maximum intensity on 25 April (Meteo France La Reunion 2019). From Table 3, the signal of 6+ and 5- dominates on this day. Hence it can be inferred that unlike TC Idai, the reason why TC Kenneth remained most active at the northern Mozambique Channel during its maximum intensity on 25 April can be partly as a result of the stronger signal of 5-, followed by $6+$ which both favors the buildup of TC towards the north of the Channel, basin-wide warming of the southwest India Ocean and enhancement of the cross-equatorial northeast trade winds steering the TC southwestward. On 26 April 5- occurred only at 11:00 UTC, whereas the occurrence of $2+, 3+$, and $9+$ which are all in favor of the stronger west to east progression of the semi-permanent high-pressure system can counter the warm SST in the southwest Indian Ocean induced from the previous day synoptic states. Though from Table 3,26 April, the signal of 5- dominates, the SLP field of 26 April (Fig. 6) clearly shows the low-pressure system located further south away from the Channel, where it will be possibly weakened by the eastward-moving high-pressure systems. 


\section{Conclusions}

In this study, the relationship between large-scale circulation patterns and storms that form in the Mozambique Channel was investigated. Using circulation typing, CTs were classified in Africa south of the equator and the CTs that have characteristics favoring the development of TC in the Mozambique Channel were noted. The result showed that during austral summer, two CTs that are mean patterns of atmospheric circulation form two scenarios of variability in the strength and location of the western branch of the Mascarene high. The first is characterized by (i) stronger circulation at the western branch of the Mascarene high, ridging into eastern South Africa, (ii) strengthening of the penetration of southeast trade winds in the Channel. The other scenario is associated with (i) weaker and more eastward state of the Mascarene high allowing cyclonic activity to enhance further southwest, (ii) enhanced cross-equatorial northeast winds. These CTs overlap with the other summer dominant CT and this suggests that the dominating pattern of atmospheric circulation at a given time is likely to be due to the occurrence of these CTs together with other CTs that have similar circulation characteristics with either of the two dominant CTs.

During the maximum intensity of cyclone Idai on 11 March, the circulation at the western branch of the Mascarene high was strong and this can be partly attributed to the finding that two days before the TC reached its maximum intensity, there was the gradual enhancement of the CTs that favor atmospheric blocking by the Mascarene high; the dominance of the CTs reached a culmination on 11 March. An enhanced circulation at the western branch of the Mascarene high implies that southeasterly anomalies will further penetrate the Channel favoring convergence with northeast winds. The vorticity and pressure drop induced by the convergence in the Mozambique Channel is likely to have contributed to why TC Idai remained most active in the Mozambique Channel. The synoptic situations during TC Kenneth featured a different Scenario; the blocking by the Mascarene high was gradually displaced by the occurrence of CTs favoring the weakening of the western branch of the Mascarene high, and enhancement of northeast winds. The TC Kenneth which formed north of Madagascar seems to be steered by northeast winds towards northern Mozambique and then southwards away from the Mozambique Channel.

For the Mozambique Channel, as a rule of thumb it can be hypothesized that when the western branch of the Mascarene high is most active, a strong TC might be centered in the Mozambique Channel so that Madagascar is mostly at risk since the strong cyclone will equally adjust easterlies towards Madagascar. On the other hand, when the western branch of the Mascarene high is weakened and more eastward, the TC, which normally develops north of Madagascar, might be driven southwestward by enhanced northerly winds so that the eastern regions of southern Africa especially Mozambique - might be at risk. Reason (2007) reported that during TC Dera, northerly currents steered the TC southward out of the Mozambique Channel. Also, it was found that low-frequency modes of variability in the south Indian Ocean are related to the CTs through SST anomalies in the southwest Indian Ocean and adjustment of the strength and position of the western branch of the Mascarene high.

Finally, through the characterization of variability in the strength and position of the semi-permanent highs, and cyclonic anomaly that form in the Mozambique Channel - in the form of recurrent patterns - during the 2019 TC season of TC Idai and TC Kenneth, the classification output reveals meaningful information on how different synoptic states might have contributed to the formation and track of the TC. Hence this study adds to the vast applications of synoptic climatology, that truly recurrent large-scale patterns might play some role in the formation and track of tropical cyclones even in the Mozambique Channel.

\section{Declarations}

Funding statement: This research received no specific grant from any funding agency in the public, commercial, or not-for-profit sectors.

Author's contribution: the paper was initiated by Chibuike Ibebuchi and work was executed by Chibuike Ibebuchi

Conflict of Interest: there are no conflicts of interest

\section{References}

1. Ash, K., C. J. Matyas, 2012: The influences of ENSO and the Subtropical Indian Ocean Dipole on tropical cyclone trajectories in the South Indian Ocean. International Journal of Climatology 32(1)41-56. https://doi.org/10.1002/joc.2249

2. Bartoszek, K., D. Skiba, 2016: Circulation types classification for hourly precipitation events in Lublin (East Poland). Open Geosciences, 8,1. https://doi.org/10.1515/geo-2016-0019

3. Cattel, R.B., 1966: The Scree Test for the Number of Factors. Multivariate Behavioural Research, 2,245-276.

https//doi:10.1207/s15327906mbr0102_10.

4. Chikoore, H., J.H. Vermeulen, M.R. Jury, 2015: Tropical cyclones in the Mozambique Channel: January-March 2012. Natural Hazards, 77, 20812095. https://doi.org/10.1007/s11069-015-1691-0

5. Compagnucci, R.H., N.E. Ruiz, 1992: On the Interpretation of Principal Component Analysis applied to meteorological data. In Proceedings of the Fifth International Meeting on Statistical Climatology. Atmospheric Environmental Service of Canada: Toronto; 241-244

6. Compagnucci, R.H., M.B. Richman, 2008: Can principal component analysis provide atmospheric circulation or teleconnection patterns? International Journal of Climatology, 6,703-726. https://doi.org/1002/joc.1574

Page 8/16 
7. Fitchett, J.M., 2018: Recent emergence of CAT5 tropical cyclones in the South Indian Ocean. South African Journal of Science, $114,1-6$. https://doi.org/10.17159/sajs.2018/4426

8. Gray, W.M., 1968: A global view of the origin of tropical disturbances and storms. Monthly Weather Review, 96,669-700. https://doi.org/10.1175/1520-0493(1968)096<0669:GVOTOO>2.0.CO;2

9. Gong X., M. B. Richman, 1995: On the application of cluster analysis to growing season precipitation data in North America east of the Rockies. Journal of Climate, 8, 897-931, DOI:10.1175/15200442(1995)008<0897:0TAOCA>2.0.CO;2

10. Gray W. M., J. D. Sheaffer, 1991: El Niños and QBO influences on tropical cyclone activity. Teleconnections linking worldwide climate anomalies. Glantz M.H., R. W. Katz, N. Nicholls (eds). Cambridge University Press: Cambridge, UK; 535

11. Harr, A.P., R.L. Elsberry, 1995: Large-scale circulation variability over the Tropical Western North Pacific. Part 1: spatial patterns and tropical cyclone characteristics. Monthly Weather Review, 5, 1225-1246. https://doi.org/10.1175/1520-0493(1995)123<1225:LSCVOT>2.0.CO;2

12. Hersbach, H., B. Bell, Berrisford, S. Hirahara, A. Horányi, J. Muñoz-Sabater, J. Nicolas, C. Peubey, and R. Radu, 2020: The ERA5 global reanalysis. Quarterly Journal of the Royal Meteorological Society, 730, 1999-2049. https://doi.org/10.1002/qj.3803

13. Jury, M.R., B. Pathack, 1991: A study of climate and weather variability over the tropical Southwest Indian Ocean. Meteorology and Atmospheric Physics, 47, 37- 48. https://doi.org/10.1007/BF01025825

14. Jury, M. R. 1993: A preliminary study of climatological associations and characteristics of tropical cyclones in the SW Indian Ocean. Meteorology and Atmospheric Physics, 51, 101-115. https://doi.org/10.1007/BF01080882

15. Kalnay, E., M. Kanamitsu, R. Kistler, W. Collins, D. Deaven, L. Gandin, M. Iredell, S. Saha, G. White, and J. Woollen, 1996: The NCEP/NCAR 40-year reanalysis project. Bulletin of the American Meteorological Society, 3,437-472. https://doi.org/10.1175/15200477(1996)077<0437:TNYRP>2.0.C0;2

16. Klinman, M.G., J.C. Reason, 2008: On the peculiar storm track of TC Favio during the 2006-2007 Southwest Indian Ocean tropical cyclone season and relationships to ENSO. Meteorology and Atmospheric Physics, 100, 233-242. https://doi.org/10.1007/s00703-008-0306-7

17. Malan, N., C.J.C. Reason, B.R. Loveday, 2013: Variability in tropical cyclone heat potential over the Southwest Indian Ocean. Journal of Geophysical Research: Oceans, 118, 6734-6746. https://doi.org/10.1002/2013JC008958

18. Malherbe, J., F. Engelbrecht, W. Landman, C. Engelbrecht, 2011: High resolution model projections of tropical cyclone landfall over southern Africa under enhanced anthropogenic forcing. South African Society for Atmospheric Sciences 27th Annual Conference, Hartbeespoort, NorthWest Province, South Africa, 22-23 September 2011.http://hdl.handle.net/10204/5680

19. Malherbe, J., F.A. Engelbrecht, W.A. Landman, 2013: Projected changes in tropical cyclone climatology and landfall in the Southwest Indian Ocean region under enhanced anthropogenic forcing. Climate Dynamics, 40, 2867-288. https://doi.org/10.1007/s00382-012-1635-2

20. Maoyi, M.L., B.J. Abiodun, J. M. Prusa, J. J. Veitch, 2018: Simulating the characteristics of tropical cyclones over the southwest Indian Ocean using a Stretched-Grid Global Climate Model. Climate Dynamics, 50, 1581-1596. https://doi.org/10.1007/s00382-017-3706-X

21. Matyas, C.J., 2015: Tropical cyclone formation and motion in the Mozambique Channel. J. Climatol., 3,375-390. https://doi.org/10.1002/joc.3985

22. Meteo France La Reunion, 11 March 2019: Tropical Cyclone Idai Warning 12. Archived from the original (PDF) on 13 March 2019. Retrieved 13 August 2020. http://www.meteo.fr/temps/domtom/La_Reunion/webcmrs9.0/anglais/activiteope/bulletins/cmrs/CMRSA_201903111200_IDAl.pdf

23. Meteo France La Reunion, 12 March 2019: Tropical Cyclone Idai Warning 15. Archived from the original (PDF) on 12 March 2019. Retrieved 13 August

2020.http://www.meteo.fr/temps/domtom/La_Reunion/webcmrs9.0/anglais/activiteope/bulletins/cmrs/CMRSA_201903120600_IDAI.pdf

24. Meteo France La Reunion, 25 April 2019: Intense Tropical Cyclone 14 (Kenneth) Warning 11. Archived from the original (PDF) on 25 April 2019. Retrieved 13 August 2020.http://www.meteo.fr/temps/domtom/La_Reunion/webcmrs9.0/anglais/activiteope/bulletins/cmrs/CMRSA_201904250600_KENNETH.pdf

25. Mofor, L.A., C. Lu, 2009: Generalized moist potential vorticity and its application in the analysis of atmospheric flows. Progress in Natural Science, 3,285-289.https://doi.org/10.1016/j.pnsc.2008.07.009.

26. Muthige, M.S., J. Malherbe, F.A. Englebrecht, S. Grab, A. Beraki, T.R. Maisha, J. Van der Merwe, 2018: Projected changes in tropical cyclones over the South West Indian Ocean under different extents of global warming. Environmental Research Letters, 13, 065019. https://doi.org/10.1088/1748-9326/aabc60

27. North, G., T. Bell, F. R. Cahalan, F. J. Moeng, 1982: Sampling errors in the estimation of empirical orthogonal functions. Monthly Weather Review, 110, 699-706. https://doi.org/10.1175/1520-0493(1982)110<0699:SEITEO>2.0.CO;2

28. Oguejiofor, C. N., B. J. Abiodun, 2019: Simulating the influence of sea-surface-temperature (SST) on tropical cyclones over South-West Indian ocean, using the UEMS-WRF regional climate model. arXiv preprint arXiv:1906.08298

29. Pillay, M.T., J.M. Fitchett, 2019: Tropical cyclone landfalls south of the Tropic of Capricorn, southwest Indian Ocean. Climate Research, 79, $23-37$. https://doi.org/10.3354/cr01575

Page 9/16 
30. Pillay, M.T., J.M. Fitchett, 2020: Southern hemisphere tropical cyclones: A critical analysis of regional characteristics. International Journal of Climatology 41,146-61. https://doi.org/10.1002/joc.6613

31. Preisendorfer, R.W., F.W. Zwiers, T.P. Barnett, 1981: Foundations of Principal Component Selection Rules. SIO, Reference Series 81-4, Scripps Institute of Oceanography, La Jolla, CA

32. Reason, C.J.C., 2002: Sensitivity of the southern African circulation to dipole sea-surface temperature patterns in the south Indian Ocean. International Journal of Climatology, 4,377-393. https://doi.org/10.1002/joc.744

33. Reason, C.J.C., 2007: Tropical cyclone Dera, the unusual 2000/01 tropical cyclone season in the South West Indian Ocean and associated rainfall anomalies over Southern Africa. Meteorology and Atmospheric Physics, 97, 181-188. https://doi.org/10.1007/s00703-006-0251-2

34. Reason, C.J.C., A. Keibel, 2004: Tropical cyclone Eline and its unusual penetration and impacts over the southern African mainland. Weather and forecasting, 19,789-805. https://doi.org/10.1175/1520-0434(2004)019<0789:TCEAIU>2.0.CO;2

35. Richman, M. B., 1981: Obliquely rotated Principal Components: an improved meteorological map typing technique? Journal of Applied Meteorology and Climatology, 20, 1145-1159.https://doi.org/10.1175/1520-0450(1981)020<1145:ORPCAI>2.0.C0;2

36. Richman, M.B., 1986: Rotation of principal components International Journal of Climatology, 3,293-335. https://doi.org/10.1002/joc.3370060305

37. Smith, R. K., 2006: Lectures on tropical cyclones

38. Vicente-Serrano, S.M., J.I. López-Moreno, 2006: The influence of atmospheric circulation at different spatial scales on winter drought variability through a semi-arid climatic gradient in Northeast Spain. International Journal of Climatology, 11,1427-1453. https://doi.org/10.1002/joc.1387

39. Wilby, R.L., 1993: The influence of variable weather patterns on river water quantity and quality regimes. International Journal of Climatology. https://doi.org/10.1002/joc.3370130408

40. Xulu N.G., H. Chikoore, M.J.M. Bopape, N.S. Nethengwe, 2020: Climatology of the Mascarene High and its influence on weather and climate over southern Africa. Climate, 8,86. https://doi.org/10.3390/cli8070086

\section{Figures}



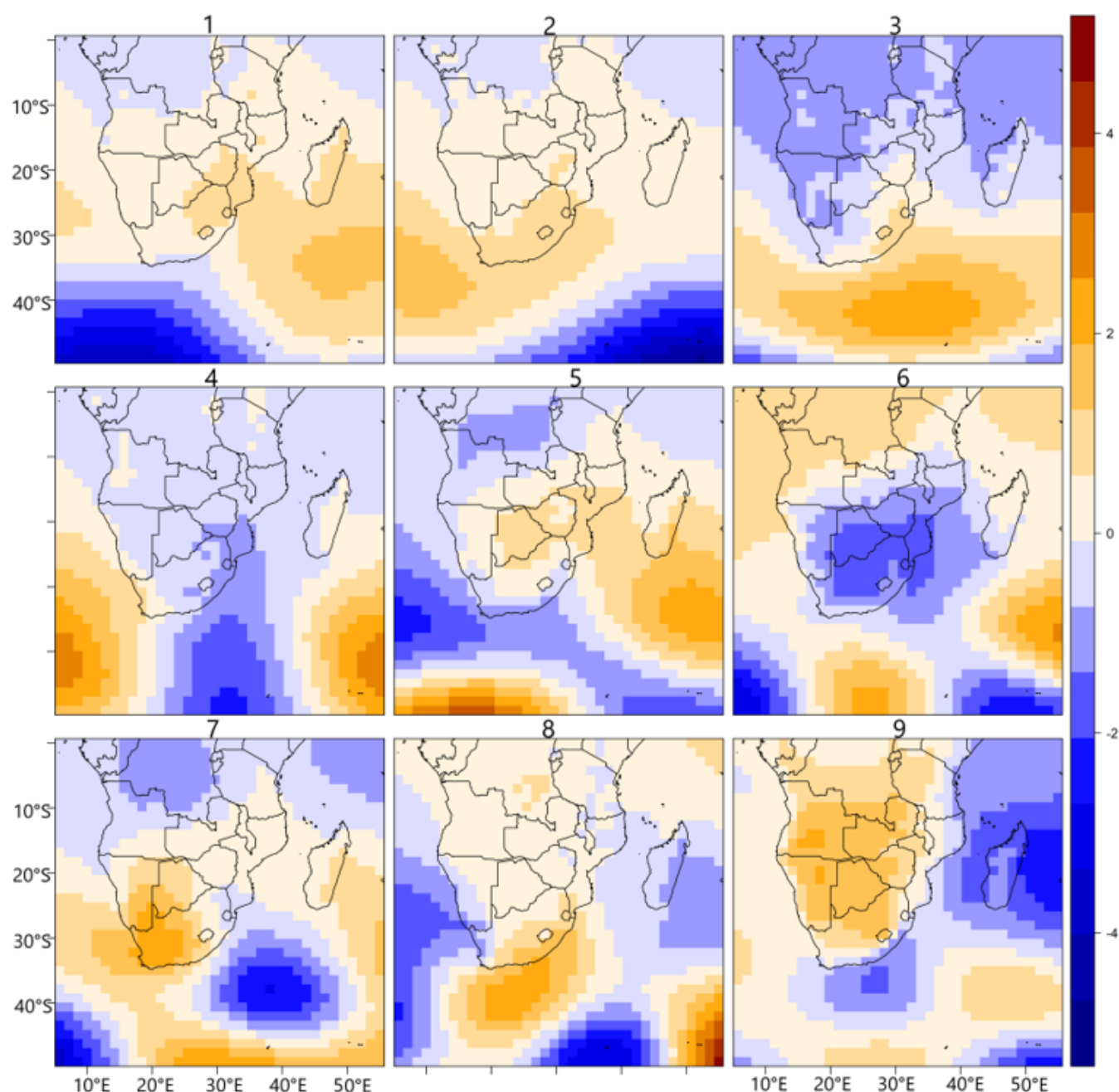

\section{Figure 1}

Input patterns in the study domain from the hourly ERA5 classification. The color bar is standardized scores from the retained components 

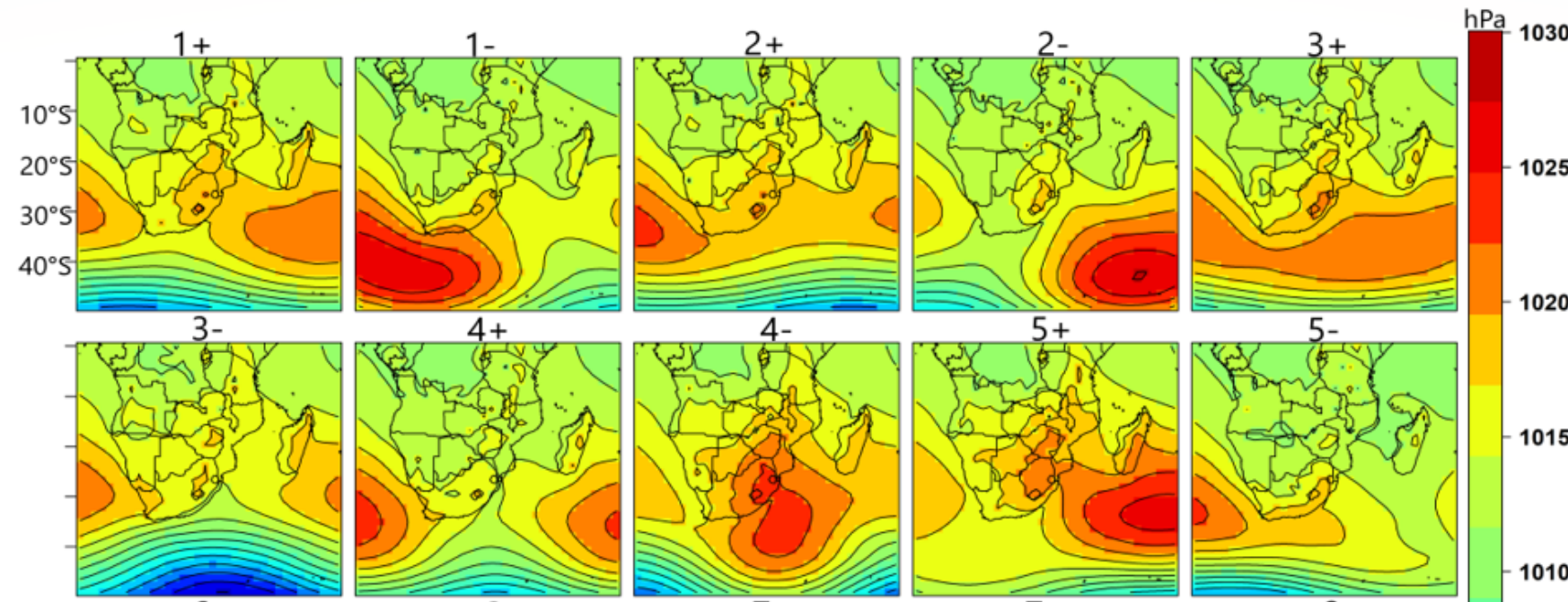

$-1020$
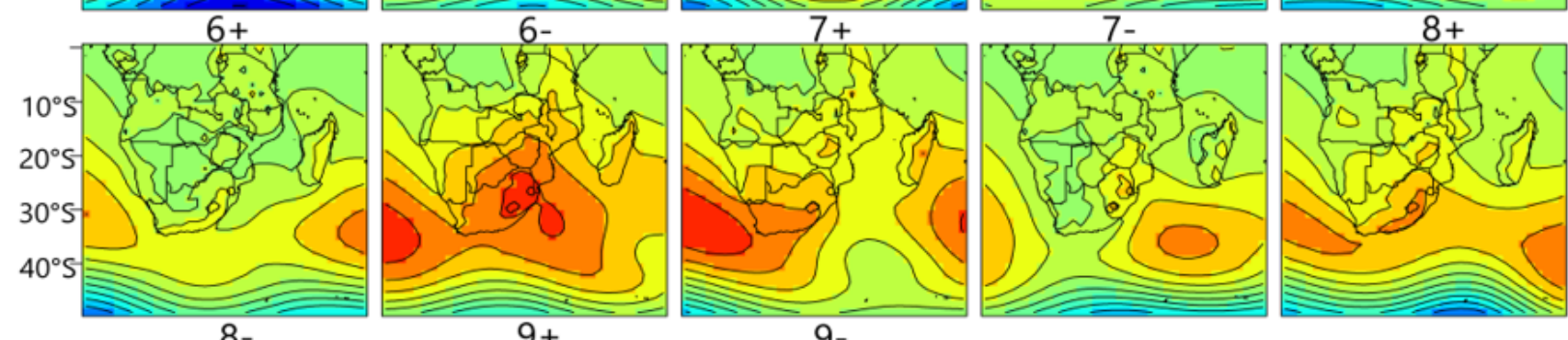

$-1010$
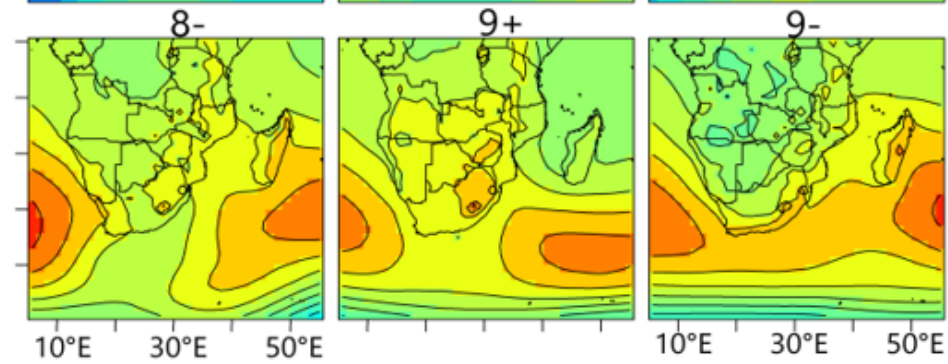

1015

1005

1000

995

Figure 2

Circulation types in the study region from the hourly ERA5 classification 


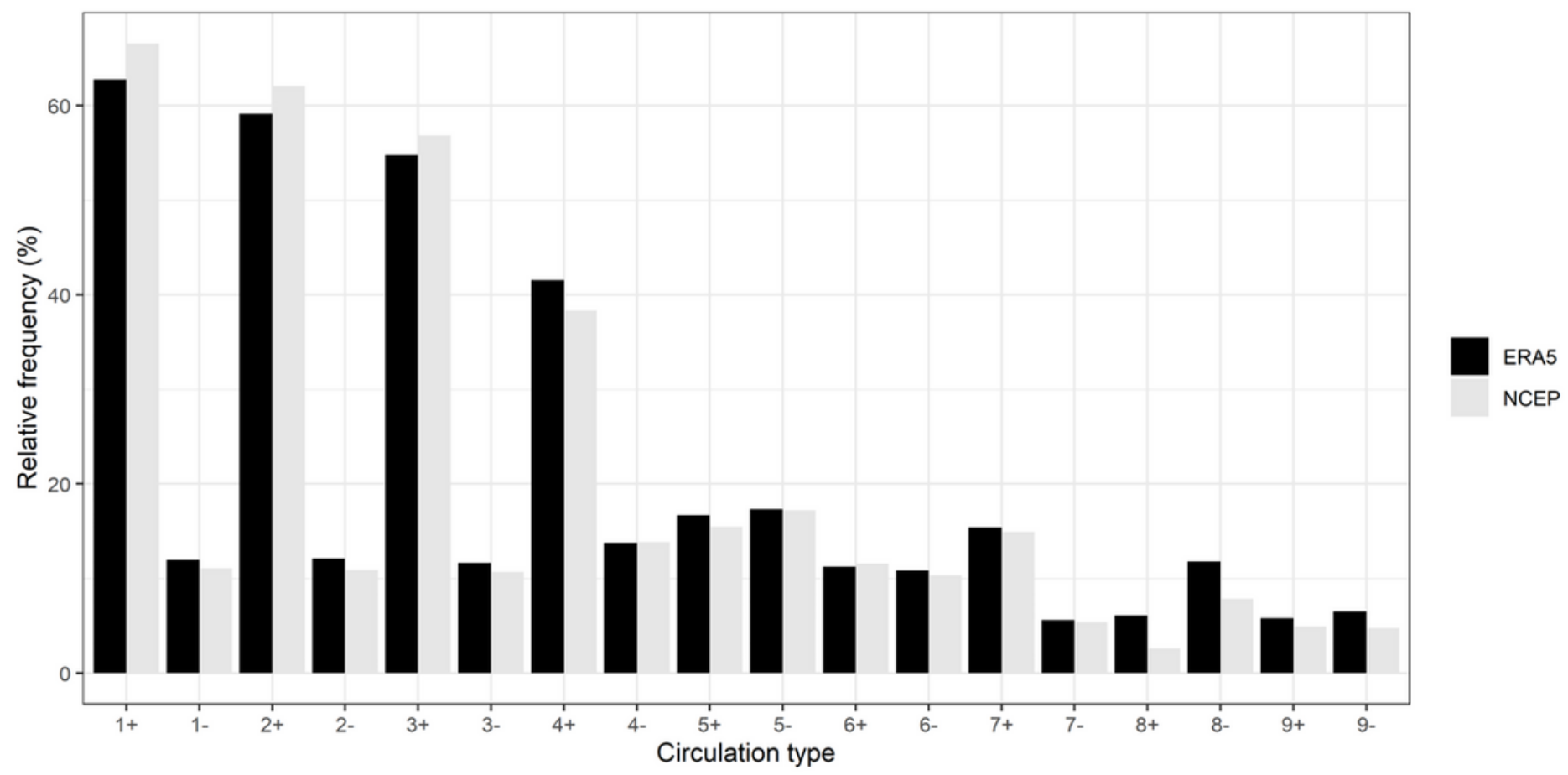

Figure 3

Comparison of the relative frequency of occurrence of the CTs from ERA5 and their counterparts from NCEP-NCAR 

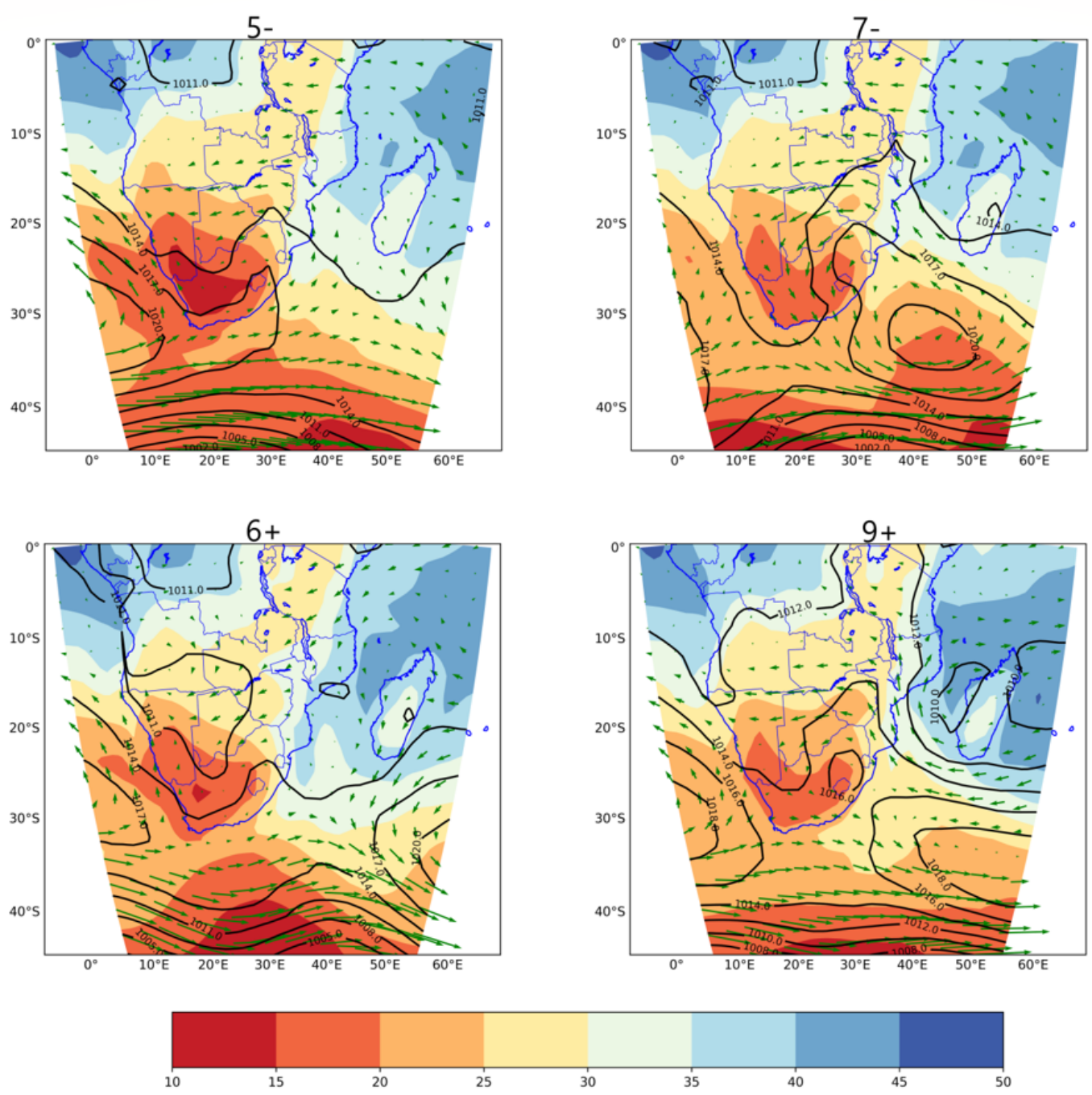

\section{Figure 4}

Composite maps for the selected CTs with TC characteristics, exemplified from NCEP-NCAR. The contour line is SLP in hPa. Vector is the wind at 850 $\mathrm{hPa}$ in $\mathrm{ms}^{\wedge}(-1)$. Color is precipitable water in $\mathrm{kg} / \mathrm{m}^{\wedge} 2$ 
$5-$

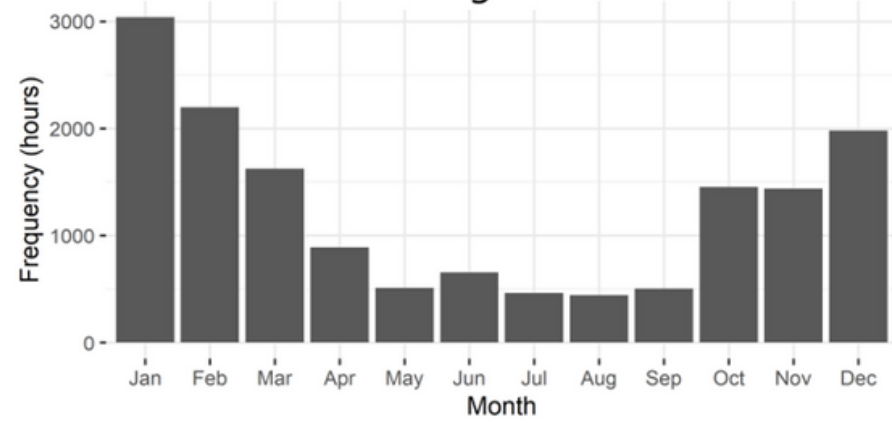

$6+$

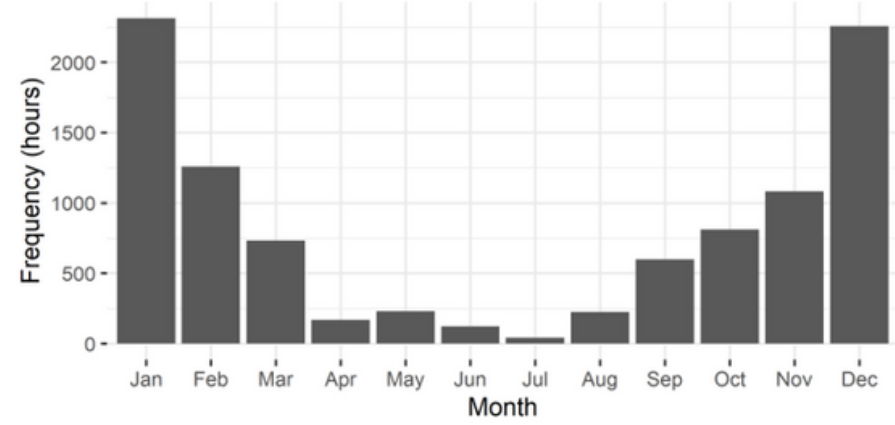

7-

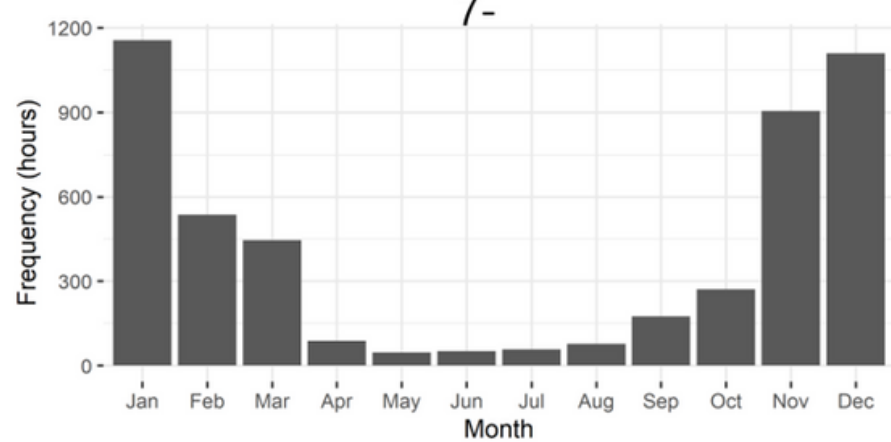

$9+$

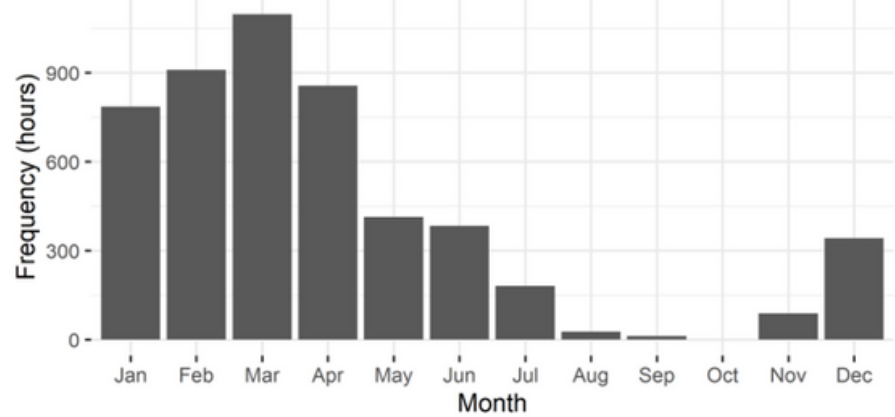

Figure 5

Annual cycle of the CTs with TC characteristics from ERA5 (top panels) and NCEP-NCAR (bottom panels) 

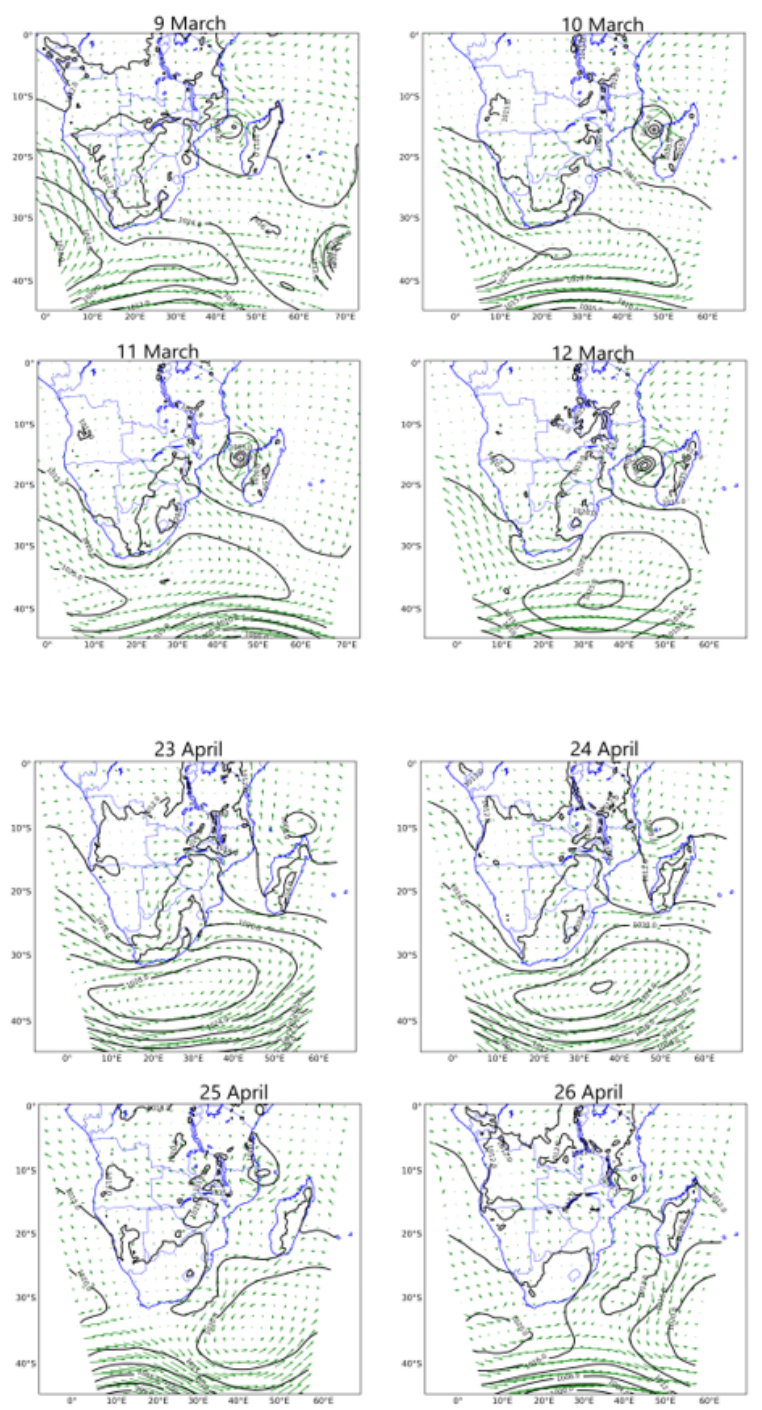

\section{Figure 6}

Daily mean SLP and vector wind on the selected days during the 2019 TC Idai and TC Kenneth in the Mozambique Channel. Contour is SLP in hPa and the green vector is the wind at $850 \mathrm{hPa}$ in $\mathrm{ms}^{\wedge}(-1)$ 